\title{
Multidisciplinary management of women with pelvic organ prolapse, urinary incontinence and lower urinary tract symptoms. A clinical and psychological overview
}

\author{
Valentina Lucia La Rosa ${ }^{1}$, Michat Ciebiera ${ }^{2}$, Li-Te Lin ${ }^{3}$, Zaki Sleiman ${ }^{4}$, Tais Marques Cerentini ${ }^{5}$, \\ Patricia Lordelo ${ }^{6}$, Ilker Kahramanogluㄱ, Simone Bruni ${ }^{8}$, Simone Garzon ${ }^{9}$, Michele Fichera $^{10}$ \\ ${ }^{1}$ Unit of Psychodiagnostics and Clinical Psychology, University of Catania, Catania, Italy \\ ${ }^{2}$ Second Department of Obstetrics and Gynecology, The Center of Postgraduate Medical Education, Warsaw, Poland \\ ${ }^{3}$ Department of Obstetrics and Gynecology, Kaohsiung Veterans General Hospital, Kaohsiung, Taiwan \\ ${ }^{4}$ Department of Obstetrics and Gynecology, Lebanese American University, Beirut, Lebanon \\ ${ }^{5}$ Postgraduate Program in Rehabilitation Sciences, Federal University of Health Sciences of Porto Alegre, Porto Alegre, Brazil \\ ${ }^{6}$ Bahiana School of Medicine and Public Health, Salvador, Brazil \\ ${ }^{7}$ Department of Obstetrics and Gynecology, Division of Gynecologic Oncology, Cerrahpasa Faculty of Medicine, Istanbul University, \\ Istanbul, Turkey \\ ${ }^{8}$ Department of Molecular and Developmental Medicine, Division of Obstetrics and Gynecology, University of Siena, Siena, Italy \\ ${ }^{9}$ Department of Obstetrics and Gynecology, “Filippo Del Ponte” Hospital, University of Insubria, Varese, Italy \\ ${ }^{10}$ Department of General Surgery and Medical Surgical Specialties, University of Catania, Catania, Italy
}

\begin{abstract}
Although female sexual dysfunctions are common among women with urogynecological conditions, they have not been thoroughly studied and there are still many questions without an answer. The recent evidence on sexual disorders in women with urogynecological diseases shows a quite wide spectrum of therapeutic approaches, which require the physicians to take into account not only the primary symptoms, but also all the associated factors negatively affected. It has been widely underlined that gynecological diseases are often associated with high stress and have a negative impact on quality of life and psychological well-being of women affected. For this reason, a multidisciplinary approach for the management of these diseases is highly recommended. Also in the case of urogynecological disorders, it is important to take into account psychological outcomes throughout the diagnostic and therapeutic process.

In the light of these considerations, the aim of this short review is to evaluate the impact of the main urogynecological diseases and the currently available therapeutic options in order to improve quality of life and sexuality of these patients and to stress the need for a multidisciplinary approach in order to minimize the negative consequences of these diseases for the sexual well-being of women and their partners.
\end{abstract}

Key words: pelvic organ prolapse, urinary incontinence, LUTS, quality of life, sexuality.

\section{Introduction}

Sexual functioning plays a relevant role in a woman's health and quality of life; therefore, sexual dysfunction may have an impact on a couple's relationship and overall quality of life [1, 2].

Sexual dysfunctions affect women more than men with about $95 \%$ of them suffering from at least one sexual problem [2]. According to McCabe's data, a large proportion of women experience multiple sexual dysfunctions [3].
Female sexual dysfunctions (FSD) are disorders encompassing sexual desire and arousal, orgasm, or dyspareunia, all conditions associated with psychological distress $[4,5]$. The most frequent sexual dysfunctions in women concern desire and arousal domains [3]. The etiology of these problems may be multifaceted, involving advanced age, chronic diseases, menopause, vaginal delivery, surgery, urinary incontinence, gynecological cancer, infertility or pelvic floor muscle (PFM) dysfunctions [6-15]. 
Although FSD are common among women with urogynecological conditions, they have not been thoroughly studied [9]. The aim of this short review is to evaluate the impact of the main urogynecological diseases and the currently available therapeutic options to improve the quality of life and sexuality of patients as well as to stress the need for a multidisciplinary approach to minimize the negative consequences of these diseases for the sexual wellbeing of women and their partners $[16,17]$.

\section{Pelvic organ prolapse}

Pelvic organ prolapse (POP) is a complex condition consisting in the failure of the supporting structures of the vagina [18] resulting in a collapse of the anterior and posterior vaginal wall, the uterus (cervix), or the apex of the vagina [19-21]. Urogenital prolapse affects about $45 \%$ of post-menopausal women, with a $30 \%$ to $50 \%$ prevalence in a lifespan [19, 22, 23]. Aging, pregnancy, delivery and history of pelvic surgery are some of the main causes of POP. Pelvic floor weakness may influence the development of POP, leading in some cases to a wider opening of the genital hiatus [24]. Brækken et al. reported that women with had the PFM more weakened, less resistant and with high vaginal resting pressure, and had higher POP incidence [25]. Moreover, some conditions that increase intra-abdominal pressure - i.e., chronic pulmonary disease, constipation, obesity and strenuous manual work - can increase the risk of POP $[19,26,27]$. The progressive ageing of the population and the recourse to surgical gynecological treatments are also underlying conditions associated with higher POP prevalence $[19,28]$. The treatment of POP relies of both non-surgical and surgical approaches. In particular, pessaries and PFM training can be useful therapeutic tools to relieve symptoms [7, 8], in addition to weight loss in the case of obesity $[26,29]$. Nevertheless, most non-surgical treatments are ineffective in the presence of severe prolapse, and surgery is the most appropriate approach in these cases. According to Barber, surgery is generally reserved for patients with bothersome prolapse symptoms who have at least stage II prolapse on examination when conservative treatments have failed or no longer work [21]. Depending on the specific instance, surgical management may consist in apical suspension (sacral colpopexy and sacrospinous ligament fixation), or anterior and posterior (colporrhaphy, perineorrhaphy and obliterative procedures) vaginal prolapse repair [30-33]. Prolapse repair basically aims to relieve the patient's symptoms, restore normal anatomy and function of the pelvic structures, prevent relapses, and correct possible intrapelvic defects [34, 35]. Surgical treatment of prolapse is contraindicated in women with local vaginal diseases, with early-stage asymptomatic prolapse, or who are unfit to undergo sur- gery [34]. Synthetic mesh has been widely used in the surgical treatment of pelvic organ prolapse but exposes women to the risk of specific complications which may require mesh removal [36-40]. In this regard, the US Food and Drug Administration (FDA) warned about serious complications associated with the transvaginal placement of mesh for POP $[41,42]$. In the same way, the International Urogynecological Association's (IUGA) Grafts Roundtable [37] advises against the use of vaginal meshes to correct POP in the presence of stage I-II, local/systemic pain syndromes, or possible pregnancy; in addition, the use of meshes does not seem to be highly effective in the case of prolapse of the posterior compartment or in women aged below 50 years; conversely, the best results seem to be achieved in women aged above 50 years, with stage II prolapse of the anterior compartment, deficient fascia, chronic increase in intra-abdominal pressure, or both, and in the case of relapses [37]. Finally, possible complications with the use of meshes have been reported either during or after prolapse correction, or intraoperatively, i.e., bleeding; injury involving the bladder, ureter or urethra, nerve or bowel; anesthesia-related complications, and deep venous thrombosis (DVT), with the subsequent risk of pulmonary embolism (PE) $[34,36]$. Postoperative complications include infections, mesh contraction or erosion through the vagina, chronic pain, recurrent voiding symptoms and sexual dysfunctions [34, 43, 44]. It is noteworthy that patients should be well aware of the possible adverse outcomes of the therapeutic approaches proposed, to allow them to agree with the urogynecologist on the most appropriate option [28, 40].

POP is quite a complex disorder, as it involves both physical and functional aspects [21, 28]. Indeed, it can significantly affect the patient's quality of life and psychological well-being, since it may be associated with a variety of urinary, bowel and sexual symptoms [19, 20]. In fact, sexual dysfunctions are very common in women with POP and cystocele [31, 32, 45], who frequently report dysfunctional sexual desire, arousal, orgasm, and pain, with possible negative implications for the relationship with their partners [28, 32]. In particular, it has been underlined that obese women with pelvic floor disorders have worse sexual function and quality of life than non-obese women [46].

Various studies have investigated changes in quality of life and sexual function of women with POP and cystocele undergoing surgical correction using vaginal mesh, with controversial results $[20,31,32,41,42$, 45, 47-51]. In fact, according to some authors, surgical management of POP and cystocele significantly improves the long-term quality of life and sexual response of these patients even if surgical approaches involving abdominal or transvaginal mesh may result in a decline in sexual function and worsening dyspareunia [31, 32, $45,52-54]$; conversely, other studies describe worsen- 
ing of the patient's sexual function and dyspareunia following mesh treatments [48-51]. Faced with this evidence, in our opinion, a multidisciplinary approach in the treatment of women with POP and cystocele is of paramount importance. General and specific questionnaires have been designed to assess quality of sexual life in women with POP before and after surgical correction. Of these, the most feasible and most commonly used are the Short Form-36 (SF-36), assessing quality of life [55], and the Female Sexual Function Index (FSFI), assessing the effects on sexual function [56]. However, the Pelvic Organ Prolapse/Urinary Incontinence Sexual Questionnaire (PISQ-12) is the most specific tool aiming to evaluate the impact of POP on these patients' sexual life [57]. Recently, the IUGA has developed a new sexual function scale, derived from the original PISQ-12 questionnaire. The IUGA Revised (PISQ-IR) questionnaire is a condition-specific tool designed to evaluate sexual function in women with POP and urinary incontinence; it is recommended to evaluate the impact of pelvic floor disorders on quality of life and sexuality of affected women [58]. Additionally, questionnaires aiming to understand the relationship between psychological symptoms and POP are a very useful tool in the preoperative assessment. In this regard, tests such as the Minnesota Multiphasic Personality Inventory-2 (MMPI-2) [59] and the Symptoms Checklist-90-R (SCL-90-R) [60] evaluate both psychopathological symptoms and personality traits and are thus able to detect possible psychological comorbidities.

Given the available evidence of the significant impact of POP on emotional health and subjective well-being, this assessment should be considered essential in the therapeutic approach to women with POP, so as to ensure more adequate physical and functional rehabilitation [61-64].

\section{Urinary incontinence}

Urinary incontinence (UI) is defined as the complaint of any involuntary leakage of urine [65]; it is a major public health issue not only for its physical, psychological and social impact on quality of life of women but also because it seems to be an important risk factor of sexual dysfunctions in both the male and female population $[9,22]$. This benign condition is quite common in women and its prevalence ranges between 11.4 and $73.0 \%$ [66]. The etiology of $\mathrm{UI}$ is multifactori$\mathrm{al}$ and is related to age and to several conditions such as overweight and obesity, diabetes, interstitial cystitis, urinary tract infections, number of pregnancies and menopause $[22,27,66,67]$. It is important to underline the close association between menopause and urinary incontinence. In this regard, several studies have confirmed that overactive bladder syndrome has a higher prevalence in menopausal women and significantly affects overall quality of life and sexual function [68-70].

A common subtype of $\mathrm{UI}$ is stress urinary incontinence (SUI), defined as a "complaint of involuntary loss of urine on effort or physical exertion including sporting activities etc., or on sneezing or coughing" [71, 72]. Its incidence is estimated to be about $15-20 \%$ of adult women [73].

The main disorders ensuing from the association between UI and FSD are poor lubrication, painful sexual intercourse and a negative impact on several psychosexual domains (sexual satisfaction, negative body image, mood, self-esteem and poor relations) [74-76]. Women with SUI tend to avoid occasions of sexual intercourse in order to prevent embarrassment caused by nighttime incontinence or leakage during intercourse $[66,72,77,78]$. These situations are common causes of depression and may be associated with disorders of arousal and desire, poor lubrication, anorgasmia, and dyspareunia [4, 9, 66, 76]. Symptomatic urinary tract infections can also be an underlying cause of emotional distress and low self-esteem, thus contributing to sexual dysfunctions and other complications [72].

Overall, to the best of our knowledge, most of the studies dealing with these issues are characterized by important limitations regarding the selection of the population sample, differences in study designs, and improper categorization of type of UI [22].

Treatment of urinary dysfunction relies on behavioral, pharmacological and surgical therapy [79]. The decision of the most suitable treatment option is based on various variables, including patient's history, age, severity of condition, subjective symptoms, obesity, as well as on the results of the specific clinical and instrumental examinations performed $[22,79,80]$.

Pure urgency incontinence is usually pharmacologically treated, whereas SUI generally requires surgical correction $[75,81]$.

Women affected by urge incontinence seem to benefit from a combination of supervised behavioral approaches (including PFM exercise instruction, strategies to suppress urge, timed voiding, and fluid management) and antimuscarinic treatment to reduce overactive bladder symptoms and urinary incontinence during sexual intercourse and orgasm [77, 82]. Pelvic floor muscle training (PFMT) is used in conservative treatments for all types of urinary incontinence and showed an improvement of functional parameters of desire, arousal and orgasm domains [66].

Gubbiotti et al. highlight that mirabegron is effective both to control urinary symptoms in women with overactive bladder and to improve their sexual life [83].

There is still little agreement on the role of estrogen therapy in menopausal symptoms and urinary incontinence $[84,85]$. The Women's Health Initiative (WHI) trial showed increased incidence of urgency, stress, and 
mixed incontinence in women after one year of treatment with estrogen and medroxyprogesterone acetate [86]. However, the population sample for this study was not selected to evaluate urinary incontinence; patients' data were collected by means of self-report questionnaires, and age at start of estrogen therapy was distributed over a wide range. All these factors may possibly account for the discrepancies with the other reports and reduce the value of the study. In this regard, other studies have reported that oral estrogen therapy increases the maximum urethral closure pressure (MUCP) in women affected by SUI [87], thus improving some postmenopausal symptoms such as urinary frequency, nocturia and recurrent infections [88].

According to other authors, although oral and local estrogen therapy does not improve SUI per se, it is able to improve subjective symptoms in some cases $[89,90]$; in these patients, a behavioral approach such as perineal pelvic rehabilitation and reinforcement of periurethral muscles can be considered the treatment of choice [91, 92].

Another therapeutic option for female urinary incontinence is correction by means of mini-invasive surgery, using tension-free suburethral slings. In particular, the recently developed transobturator tape (TOT) ensures good results and is associated with lower intraoperative morbidity and hospitalization times as well as fewer postoperative complications [54, 73, 80, 93].

Moreover, both TOT and tension-free vaginal tape (TVT) improve the elasticity of the vaginal and clitoral blood flow, positively influencing sexual activity of women with SUI [94].

Recently, Blaivas et al. described the operative technique of autologous fascial pubovaginal sling (AFPVS) surgery comparing safety and efficacy of this technique with those of the synthetic midurethral sling. While the sling is associated with more severe complications, AFPVS seems to be the gold standard for the treatment of SUI [95].

Vaginal pessaries are an effective conservative treatment characterized by a rather low complications rate and high level of satisfaction of women treated with this device [96].

Finally, laser therapy seems to be a promising treatment option for genitourinary syndrome of menopause, vaginal laxity, and stress urinary incontinence symptoms. However, the IUGA committee opinion underlines that the therapeutic advantages of nonsurgical laser-based devices in urogynecology can only be recommended after robust clinical trials have demonstrated their longterm complication profile, safety, and efficacy [97].

\section{Lower urinary tract symptoms}

Lower urinary tract symptoms (LUTS) are characterized by a set of symptoms related to the bladder fill- ing phase and include a higher frequency of daily and nocturnal voiding, defined as daytime and nighttime pollakiuria [98]. LUTS are very common among women and can significantly affect their physiological, social and sexual life [98-100].

Endometriosis may be a significant cause of urinary symptoms. In this regard, it has been widely demonstrated that surgery for deep infiltrating endometriosis (DIE) is associated with a high rate of urinary side effects with a significantly negative impact on quality of life in about $20 \%$ of patients [101]. In addition, urinary tract endometriosis (UTE) may cause LUTS such as frequency, dysuria, and hematuria [102, 103].

At variance with UI, only a small number of studies has investigated sexual dysfunctions in women with LUTS, and many of them are flawed by several methodological problems, such as the use of different psychometric instruments and indexes to evaluate patients' sexual wellbeing [22]. Most studies have shown how LUTS can negatively affect a woman's sexuality, considering coital pain disorders as the most common sexual problem reported by patients with bladder dysfunction $[104,105]$. Indeed, LUTS are frequently associated with female genital inflammation and poor vaginal lubrication during sexual intercourse [104].

In this regard, Moller et al. suggested that presence of female sexual dysfunctions and the consequent restraint in sexual activity may increase the occurrence of LUTS; in fact, these authors observed a 3- to 6-fold higher prevalence of LUTS in women who curtailed their sexual activity in comparison to those who were sexually active, and a non-significant decrease of LUTS in women who became again sexually active [99].

\section{Discussion and conclusions}

Recent evidence about sexual disorders in women with urogynecological diseases shows quite a wide spectrum of therapeutic approaches, which require the physicians to take into account not only the primary symptoms, but also all the associated factors negatively affected by urogynecological symptoms. For instance, there is controversy over the results of estrogen therapy [86] - although it is specifically indicated in given conditions, such as in the presurgical management of POP [19], and seems to have a favorable effect on the subjective symptoms associated with urogynecological symptoms [77, 86, 88]. The behavioral approach also seems to have a positive effect on the treatment process, along with surgical correction [33].

It has been widely underlined that gynecological diseases are often associated with high stress and have a negative impact on the quality of life and psychological well-being of the women affected [8, 106-116]. For this reason, a multidisciplinary approach to the management of these diseases is highly recommended [117]. 
Also in the case of the urogynecological disorders, it is important to take into account psychological outcomes throughout the diagnostic and therapeutic process [118]. Firstly, adequate preliminary clinical and instrumental assessment of the urogynecological disorder is needed to correctly assign the patient to the most suitable medical and/or surgical therapeutic approach. The overall evaluation of the dysfunction from both a psychological and sexual point of view, possibly including sexological counseling, is of paramount importance. Indeed, both domains play an extremely important role in a woman's overall well-being and quality of life $[28,77,98,119]$. For this purpose, the use of validated instruments to assess the impact of urogynecological disorders on quality of life and female sexual function is advisable [120]; in particular, this should become an integral part of the therapeutic process to limit as much as possible the undesirable consequences of these diseases. For this purpose, it is crucial to identify simple and efficient standards for good counseling of the patient in order to choose the best therapeutic option for each woman.

\section{Disclosure}

The authors report no conflict of interest.

\section{References}

1. Education and treatment in human sexuality: the training of health professionals. Report of a WHO meeting. World Health Organ Tech Rep Ser 1975: 5-33.

2. Buster JE. Managing female sexual dysfunction. Fertil Steril 2013; 100: 905-915.

3. McCabe MP, Sharlip ID, Lewis R, et al. Incidence and Prevalence of Sexual Dysfunction in Women and Men: A Consensus Statement from the Fourth International Consultation on Sexual Medicine 2015. J Sex Med 2016; 13: 144-152.

4. Dalpiaz O, Kerschbaumer A, Mitterberger M, et al. Female sexual dysfunction: A new urogynaecological research field. BJU Int 2008; 101: 717-721.

5. Berman JR, Adhikari SP, Goldstein I. Anatomy and physiology of female sexual function and dysfunction: classification, evaluation and treatment options. Eur Urol 2000; 38: 20-29.

6. Graziottin A. Sexual function in women with gynaecologic cancer. A review. Ital J Gynaecol Obstet 2001; 13: 61-68.

7. Carter J, Stabile C, Gunn A, et al. The Physical Consequences of Gynecologic Cancer Surgery and Their Impact on Sexual, Emotional, and Quality of Life Issues. J Sex Med 2013; 10: 21-34.

8. Vitale SG, La Rosa VL, Rapisarda AMC, et al. Psychology of infertility and assisted reproductive treatment: the Italian situation. J Psychosom Obstet Gynecol 2017; 38: 1-3.

9. Sarikaya S, Yildiz FG, Senocak C, et al. Urinary incontinence as a cause of depression and sexual dysfunction: Questionnaire-based study. Rev Int Androl 2018 Nov 20. pii: S1698-031X(18)30082-7. doi: 10.1016/j.androl.2018.08.003 [Epub ahead of print].

10. Caruso S, Cianci S, Vitale SG, et al. Sexual function and quality of life of women adopting the levonorgestrel-releasing intrauterine system (LNGIUS 13.5 mg) after abortion for unintended pregnancy. Eur J Contracept Reprod Health Care 2018; 23: 24-31.

11. Palacios S, Castelo-Branco C, Currie H, et al. Update on management of genitourinary syndrome of menopause: A practical guide. Maturitas 2015; 82: 307-312
12. Peri L, Musquera M, Vilaseca A, et al. Perioperative outcome and female sexual function after laparoscopic transvaginal NOTES-assisted nephrectomy. World J Urol 2015; 33: 2009-2014.

13. Ozdemir FC, Pehlivan E, Melekoglu R. Pelvic floor muscle strength of women consulting at the gynecology outpatient clinics and its correlation with sexual dysfunction: A cross-sectional study. Pakistan J Med Sci 2017; 33: 854-859.

14. Laganà AS, Vitale SG, Stojanovska L, et al. Preliminary results of a singlearm pilot study to assess the safety and efficacy of visnadine, prenylflavonoids and bovine colostrum in postmenopausal sexually active women affected by vulvovaginal atrophy. Maturitas 2018; 109: 78-80.

15. Vitale SG, Capriglione S, Zito G, et al. Management of endometrial, ovarian and cervical cancer in the elderly: current approach to a challenging condition. Arch Gynecol Obstet 2019; 299: 299-315.

16. Culligan PJ, Haughey S, Lewis C, et al. Sexual Satisfaction Changes Reported by Men After Their Partners' Robotic-Assisted Laparoscopic Sacrocolpopexies. Female Pelvic Med Reconstr Surg 2019; 25: 365-368.

17. Lim R, Liong ML, Leong WS, et al. Sexual Function in Couples With or Without Female Incontinent Partners: Correlates and Predictors. Urology 2018; 112: 46-51.

18. Togami JM, Brown E, Winters JC. Vaginal mesh - the controversy. F1000 Med Rep 2012; 4: 21.

19. Choi KH, Hong JY. Management of pelvic organ prolapse. Korean J Uro 2014; 55: 693-702.

20. Hefni M, Barry JA, Koukoura O, et al. Long-term quality of life and patient satisfaction following anterior vaginal mesh repair for cystocele. Arch Gynecol Obstet 2013; 287: 441-446.

21. Barber MD. Pelvic organ prolapse. BMJ 2016; 354: i3853.

22. Mollaioli D, Lin L-T, Shah M, et al. Multidisciplinary management of sexual quality of life among menopausal women with urogynecological complains. Ital J Gynaecol Obstet 2018; 30: 15-20.

23. Caruso S, Cianci S, Vitale SG, et al. Effects of ultralow topical estriol dose on vaginal health and quality of life in postmenopausal women who underwent surgical treatment for pelvic organ prolapse. Menopause 2017; 24: 900-907.

24. Chen L, Ashton-Miller JA, Hsu Y, et al. Interaction Among Apical Support, Levator Ani Impairment, and Anterior Vaginal Wall Prolapse. Obstet Gynecol 2006; 108: 324-332.

25. Braekken I, Majida M, Ellström Engh M, et al. Pelvic floor function is in dependently associated with pelvic organ prolapse. BJOG An Int J Obstet Gynaecol 2009; 116: 1706-1714.

26. Pomian A, Lisik W, Kosieradzki M, et al. Obesity and Pelvic Floor Disorders: A Review of the Literature. Med Sci Monit 2016; 22: 1880-1886.

27. Obara-Gołebiowska M. Quality of life in obesity at perimenopausal age in obese women and women with proper body mass index. Heal Probl Civiliz 2018; 12: 151-156.

28. Laganà AS, La Rosa VL, Rapisarda AMC, et al. Pelvic organ prolapse: The impact on quality of life and psychological well-being. J Psychosom Obstet Gynecol 2018; 39: 164-166.

29. Lee UJ, Kerkhof MH, van Leijsen SA, et al. Obesity and pelvic organ prolapse. Curr Opin Urol 2017; 27: 428-434.

30. Vitale SG, Laganà AS, Noventa M, et al. Transvaginal Bilateral Sacrospinous Fixation after Second Recurrence of Vaginal Vault Prolapse: Efficacy and Impact on Quality of Life and Sexuality. Biomed Res Int 2018; 2018: 5727165.

31. Vitale SG, Caruso S, Rapisarda AMC, et al. Biocompatible porcine dermis graft to treat severe cystocele: impact on quality of life and sexuality. Arch Gynecol Obstet 2016; 293: 125-131.

32. Caruso S, Bandiera S, Cavallaro A, et al. Quality of life and sexual changes after double transobturator tension-free approach to treat severe cystocele. Eur J Obstet Gynecol Reprod Biol 2010; 151: 106-109.

33. Maher C, Feiner B, Baessler K, et al. Surgical management of pelvic organ prolapse in women. Cochrane Database Syst Rev 2013: CD004014.

34. Ellington DR, Richter HE. Indications, contraindications, and complications of mesh in surgical treatment of pelvic organ prolapse. Clin Obstet Gynecol 2013; 56: 276-288.

35. Slopnick EA, Petrikovets A, Sheyn D, et al. Surgical trends and patient factors associated with the treatment of apical pelvic organ prolapse from a national sample. Int Urogynecol J 2019; 30: 603-609.

36. Yakasai IA, Bappa LA, Paterson A. Outcome of repeat surgery for genital prolapse using prolift-mesh. Ann Surg Innov Res 2013; 7: 3. 
37. Davila GW, Baessler K, Cosson M, et al. Selection of patients in whom vaginal graft use may be appropriate. Consensus of the 2nd IUGA Grafts Roundtable: optimizing safety and appropriateness of graft use in transvaginal pelvic reconstructive surgery. Int Urogynecol J 2012; 23 Suppl 1: S7-14

38. Monti M, Schiavi MC, Colagiovanni V, et al. Effectiveness, quality of life and sexual functions in women with anterior compartment prolapse treated by native tissue repair: a mini-review. Minerva Ginecol 2019; 71: $18-24$

39. Duckett J, Morley R, Monga A, et al. Mesh removal after vaginal surgery: what happens in the UK? Int Urogynecol J 2017; 28: 989-992.

40. Kowalik CR, Lakeman MME, de Kraker AT, Roovers JPWR. Effects of meshrelated complications in vaginal surgery on quality of life. Int Urogynecol J 2019; 30: 1083-1089.

41. U.S. Food and Drug Administration. FDA Public Health Notification: Serious Complications Associated with Transvaginal Placement of Surgica Mesh in Repair of Pelvic Organ Prolapse and Stress Urinary Incontinence 2008.

42. U.S. Food and Drug Administration. FDA Safety Communication: UPDATE on Serious Complications Associated with Transvaginal Placement of Surgical Mesh for Pelvic Organ Prolapse, 2011.

43. Chermansky CJ, Winters JC. Complications of vaginal mesh surgery. Curr Opin Urol 2012; 22: 287-291.

44. Vancaillie T, Tan Y, Chow J, et al. Pain after vaginal prolapse repair surgery with mesh is a post-surgical neuropathy which needs to be treated - and can possibly be prevented in some cases. Aust N Z J Obstet Gynaecol 2018; 58: 696-700.

45. Farthmann J, Mengel M, Henne B, et al. Improvement of pelvic floorrelated quality of life and sexual function after vaginal mesh implantation for cystocele: primary endpoint of a prospective multicentre trial. Arch Gynecol Obstet 2016; 294: 115-121.

46. Bilgic D, Gokyildiz S, Kizilkaya Beji N, et al. Quality of life and sexual function in obese women with pelvic floor dysfunction. Women Health 2019; 59: 101-113.

47. Weintraub AY, Neuman M, Reuven Y, et al. Efficacy and safety of skeletonized mesh implants for advanced pelvic organ prolapse: 12-month follow-up. World J Urol 2016; 34: 1491-1498.

48. Gungor T, Ekin M, Dogan M, et al. Influence of anterior colporrhaphy with colpoperineoplasty operations for stress incontinence and/or genital descent on sexual life. J Pak Med Assoc 1997; 47: 248-250.

49. Helström L, Nilsson B. Impact of vaginal surgery on sexuality and quality of life in women with urinary incontinence or genital descensus. Acta Obstet Gynecol Scand 2005; 84: 79-84.

50. Liang C-C, Tseng L-H, Lo T-S, et al. Sexual function following outside-in transobturator midurethral sling procedures: a prospective study. Int Uro gynecol I 2012; 23: 1693-1698.

51. Liang C-C, Lin Y-H, Chang Y-L, et al. Urodynamic and clinical effects of transvaginal mesh repair for severe cystocele with and without urinary incontinence. Int J Gynaecol Obstet 2011; 112: 182-186.

52. Shatkin-Margolis A, Pauls RN. Sexual function after prolapse repair. Curr Opin Obstet Gynecol 2017; 29: 343-348.

53. Oversand SH, Staff AC, Borstad E, et al. The Manchester procedure: anatomical, subjective and sexual outcomes. Int Urogynecol J 2018; 29 : 1193-1201.

54. Sharifiaghdas F, Daneshpajooh A, Mirzaei M. Simultaneous treatment of anterior vaginal wall prolapse and stress urinary incontinence by using transobturator four arms polypropylene mesh. Korean J Urol 2015; 56 811-816.

55. Ware JE, Kosinski M, Gandek B, et al. The factor structure of the SF-36 Health Survey in 10 countries: results from the IQOLA Project. International Quality of Life Assessment. J Clin Epidemiol 1998; 51: 1159-1165.

56. Rosen R, Brown C, Heiman J, et al. The Female Sexual Function Index (FSFI): a multidimensional self-report instrument for the assessment of female sexual function. J Sex Marital Ther 2000; 26: 191-208.

57. Rogers RG, Coates KW, Kammerer-Doak D, et al. A short form of the Pelvic Organ Prolapse/Urinary Incontinence Sexual Questionnaire (PISO-12). Int Urogynecol J Pelvic Floor Dysfunct 2003; 14: 164-168; discussion 168.

58. Rogers RG, Rockwood TH, Constantine ML, et al. A new measure of sexual function in women with pelvic floor disorders (PFD): the Pelvic Organ Prolapse/Incontinence Sexual Questionnaire, IUGA-Revised (PISQ-IR). Int Urogynecol J 2013; 24: 1091-1103.
59. Graham JR. MMPI-2: Assessing personality and psychopathology (4th ed.). In: MMPI-2 Assess Personal Psychopathol (4th ed.). Oxford University Press 2006

60. Prunas A, Sarno I, Preti E, et al. Psychometric properties of the Italian version of the SCL-90-R: a study on a large community sample. Eur Psychiatry 2012; 27: 591-597.

61. Ghetti C, Skoczylas LC, Oliphant SS, et al. The Emotional Burden of Pelvic Organ Prolapse in Women Seeking Treatment: A Qualitative Study. Female Pelvic Med Reconstr Surg 2015; 21: 332-338.

62. Lowder JL, Ghetti C, Nikolajski C, et al. Body image perceptions in women with pelvic organ prolapse: a qualitative study. Am J Obstet Gynecol 2011; 204: 441.e1-5.

63. Dunivan GC, Anger JT, Alas A, et al. Pelvic organ prolapse: A disease of silence and shame. Female Pelvic Med Reconstr Surg 2014; 20: 322-327.

64. Pakbaz M, Persson M, Löfgren $M$, et al. 'A hidden disorder until the pieces fall into place' - a qualitative study of vaginal prolapse. BMC Womens Health 2010; 10: 18

65. Abrams P, Cardozo L, Fall M, et al. The standardisation of terminology of lower urinary tract function: report from the Standardisation Subcommittee of the International Continence Society. Am J Obstet Gynecol 2002; 187: 116-126.

66. Mota RL. Female urinary incontinence and sexuality. Int Braz J Urol 2017; 43: 20-28.

67. Patnaik SS, Laganà AS, Vitale SG, et al. Etiology, pathophysiology and biomarkers of interstitial cystitis/painful bladder syndrome. Arch Gynecol Obstet 2017; 295: 1341-1359.

68. Hakimi S, Aminian E, Alizadeh Charandabi SM, et al. Risk factors of overactive bladder syndrome and its relation to sexual function in menopausal women. Urologia 2018; 85: 10-14.

69. Zhu L, Cheng X, Sun J, et al. Association between Menopausal Symptoms and Overactive Bladder: A Cross-Sectional Questionnaire Survey in China. PLoS One 2015; 10: e0139599.

70. Chen Y, Yu W, Yang Y, et al. Association between overactive bladder and peri-menopause syndrome: a cross-sectional study of female physicians in China. Int Urol Nephrol 2015; 47: 743-749.

71. Haylen BT, de Ridder D, Freeman RM, et al. An International Urogynecological Association (IUGA)/International Continence Society (ICS) joint report on the terminology for female pelvic floor dysfunction. Neurourol Urodyn 2010; 29: 4-20.

72. Pérez-Tomás C, Gómez-Pérez L, Romero-Maroto J, et al. Sexual Quality of Life After Treatment of Stress Urinary Incontinence With Adjustable Tension-free Mesh System in Women Who Were Sexually Active Before Surgery. Urology 2018; 115: 76-81.

73. Ko YH, Song C-H, Choi JW, et al. Effect on Sexual Function of Patients and Patients' Spouses After Midurethral Sling Procedure for Stress Urinary Incontinence: A Prospective Single Center Study. Low Urin Tract Symptoms 2016; 8: 182-185.

74. Su C-C, Sun BY-C, Jiann B-P. Association of urinary incontinence and sexual function in women. Int J Urol 2015; 22: 109-113.

75. Visser E, de Bock GH, Berger MY, et al. Impact of urinary incontinence on sexual functioning in community-dwelling older women. J Sex Med 2014; 11: 1757-1765.

76. Duralde ER, Rowen TS. Urinary Incontinence and Associated Female Sexual Dysfunction. Sex Med Rev 2017; 5: 470-485

77. Serati M, Salvatore S, Uccella S, et al. Female Urinary Incontinence During Intercourse: A Review on an Understudied Problem for Women's Sexuality. J Sex Med 2009; 6: 40-48.

78. Barber MD, Dowsett SA, Mullen KJ, et al. The impact of stress urinary incontinence on sexual activity in women. Cleve Clin J Med 2005; 72: 225-232.

79. Castro RA, Arruda RM, Bortolini MAT. Female urinary incontinence: effective treatment strategies. Climacteric 2015; 18: 135-141.

80. Linder BJ, Elliott DS. Synthetic Midurethral Slings: Roles, Outcomes, and Complications. Urol Clin North Am 2019; 46: 17-30.

81. Su C-C, Sun BY-C, Jiann B-P. Association of urinary incontinence and sexual function in women. Int J Urol 2015; 22: 109-113.

82. Lukacz ES, Santiago-Lastra Y, Albo ME, et al. Urinary Incontinence in Women. JAMA 2017; 318: 1592

83. Gubbiotti M, Giannantoni A, Cantaluppi S, et al. The impact of Mirabegron on sexual function in women with idiopathic overactive bladder. BMC Urol 2019; 19: 7 
84. Cody JD, Jacobs ML, Richardson K, et al. Oestrogen therapy for urinary incontinence in post-menopausal women. Cochrane Database Syst Rev 2012; 10: CD001405.

85. Paszkowski T, Skrzypulec-Plinta V. Assessment of quality of life in women using Femelis Meno. Menopausal Rev 2018; 17: 77-85.

86. Hendrix SL, Cochrane BB, Nygaard IE, et al. Effects of estrogen with and without progestin on urinary incontinence. JAMA 2005; 293: 935-948.

87. Dietz HP, Tekle H, Williams G. Pelvic floor structure and function in women with vesicovaginal fistula. J Urol 2012; 188: 1772-1777.

88. Cardozo L, Lose G, McClish D, et al. A systematic review of the effects of estrogens for symptoms suggestive of overactive bladder. Acta Obstet Gynecol Scand 2004; 83: 892-897.

89. Cardozo L, Drutz HP, Baygani SK, et al. Pharmacological treatment of women awaiting surgery for stress urinary incontinence. Obstet Gynecol 2004; 104: 511-519.

90. La Rosa VL, Ciebiera M, Lin L-T, et al. Treatment of genitourinary syndrome of menopause: the potential effects of intravaginal ultralow-concentration oestriol and intravaginal dehydroepiandrosterone on quality of life and sexual function. Prz Menopauzalny 2019; 18: 116-122.

91. Ignácio Antônio F, Herbert RD, Bø K, et al. Pelvic floor muscle training increases pelvic floor muscle strength more in post-menopausal women who are not using hormone therapy than in women who are using hormone therapy: a randomised trial. J Physiother 2018; 64: 166-171.

92. Parker WP, Griebling TL. Nonsurgical Treatment of Urinary Incontinence in Elderly Women. Clin Geriatr Med 2015; 31: 471-485.

93. Huang Z-M, Xiao H, Ji Z-G, et al. TVT versus TOT in the treatment of female stress urinary incontinence: a systematic review and meta-analysis. Ther Clin Risk Manag 2018; 14: 2293-2303.

94. Caruso S, Rugolo S, Bandiera S, et al. Clitoral Blood Flow Changes After Surgery for Stress Urinary Incontinence: Pilot Study on TVT Versus TOT Procedures. Urology 2007; 70: 554-557.

95. Blaivas JG, Simma-Chiang V, Gul Z, et al. Surgery for Stress Urinary Incontinence: Autologous Fascial Sling. Urol Clin North Am 2019; 46: 41-52.

96. Al-Shaikh G, Syed S, Osman S, et al. Pessary use in stress urinary incontinence: a review of advantages, complications, patient satisfaction, and quality of life. Int J Womens Health 2018; 10: 195-201.

97. Shobeiri SA, Kerkhof MH, Minassian VA, et al. IUGA committee opinion: laser-based vaginal devices for treatment of stress urinary incontinence, genitourinary syndrome of menopause, and vaginal laxity. Int Urogynecol I 2019; 30: 371-376.

98. Coyne KS, Sexton CC, Irwin DE, et al. The impact of overactive bladder, incontinence and other lower urinary tract symptoms on quality of life, work productivity, sexuality and emotional well-being in men and women: results from the EPIC study. BJU Int 2008; 101: 1388-1395.

99. Møller LA, Lose G. Sexual activity and lower urinary tract symptoms. Int Urogynecol J Pelvic Floor Dysfunct 2006; 17: 18-21.

100. Cox L, Rovner ES. Lower urinary tract symptoms in women. Curr Opin Urol 2016; 26: 328-333.

101. Ballester M, Dubernard G, Wafo E, et al. Evaluation of urinary dysfunction by urodynamic tests, electromyography and quality of life questionnaire before and after surgery for deep infiltrating endometriosis. Eur J Obstet Gynecol Reprod Biol 2014; 179: 135-140.

102. Maggiore ULR, Ferrero S, Candiani M, et al. Bladder Endometriosis: A Systematic Review of Pathogenesis, Diagnosis, Treatment, Impact on Fertility, and Risk of Malignant Transformation. Eur Urol 2017; 71: 790-807.

103. Barra F, Scala C, Biscaldi E, et al. Ureteral endometriosis: a systematic review of epidemiology, pathogenesis, diagnosis, treatment, risk of malignant transformation and fertility. Hum Reprod Update 2018; 24 : 710-730.

104. Nilsson M, Lalos O, Lindkvist $\mathrm{H}$, et al. How do urinary incontinence and urgency affect women's sexual life? Acta Obstet Gynecol Scand 2011; 90: 621-628.

105. Felippe MR, Zambon JP, Girotti ME, et al. What Is the Real Impact of Urinary Incontinence on Female Sexual Dysfunction? A Case Control Study. Sex Med 2017; 5: e54-e60.

106. Laganà AS, La Rosa VL, Rapisarda AMC, et al. Anxiety and depression in patients with endometriosis: Impact and management challenges. Int J Womens Health 2017; 9: 323-330.
107. Bellia A, Vitale SG, Laganà AS, et al. Feasibility and surgical outcomes of conventional and robot-assisted laparoscopy for early-stage ovarian cancer: a retrospective, multicenter analysis. Arch Gynecol Obstet 2016; 294: 615-622.

108. Vitale SG, Sapia F, Rapisarda AMC, et al. Hysteroscopic Morcellation of Submucous Myomas: A Systematic Review. Biomed Res Int 2017; 2017 6848250.

109. Vitale SG, La Rosa VL, Rapisarda AMC, et al. Impact of endometriosis on quality of life and psychological well-being. J Psychosom Obstet Gynaecol 2017; 38: 317-319.

110. Soliman AM, Coyne KS, Zaiser E, et al. The burden of endometriosis symptoms on health-related quality of life in women in the United States: a cross-sectional study. J Psychosom Obstet Gynaecol 2017; 38: 238-248.

111. Fagervold $B$, Jenssen $M$, Hummelshoj $L$, et al. Life after a diagnosis with endometriosis - a 15 years follow-up study. Acta Obstet Gynecol Scand 2009; 88: 914-919.

112. Chan JL, Wang ET. Oncofertility for women with gynecologic malignancies. Gynecol Oncol 2017; 144: 631-636.

113. Laganà AS, La Rosa VL, Rapisarda AMC, et al. Psychological impact of fertility preservation techniques in women with gynaecological cancer. Ecancermedicalscience 2017; 11: ed62.

114. Vitale SG, La Rosa VL, Rapisarda AMC, et al. Fertility preservation in women with gynaecologic cancer: the impact on quality of life and psychological well-being. Hum Fertil (Camb) 2018; 21: 35-38.

115. Maroufizadeh S, Karimi E, Vesali S, et al. Anxiety and depression after failure of assisted reproductive treatment among patients experiencing infertility. Int J Gynaecol Obstet 2015; 130: 253-256.

116. Izycki D, Woźniak K, Izycka N. Consequences of gynecological cancer in patients and their partners from the sexual and psychological perspective. Prz Menopauzalny 2016; 15: 112-116.

117. La Rosa VL, Valenti G, Sapia F, et al. Psychological impact of gynecological diseases: The importance of a multidisciplinary approach. Ital J Gynaecol Obstet 2018; 30: 23-26.

118. Vitale SG, La Rosa VL, Rapisarda AMC, et al. The Importance of a Multidisciplinary Approach or Women with Pelvic Organ Prolapse and Cystocele. Oman Med J 2017; 32: 263-264.

119. Athanasiou S, Grigoriadis T, Chalabalaki A, et al. Pelvic organ prolapse contributes to sexual dysfunction: a cross-sectional study. Acta Obstet Gynecol Scand 2012; 91: 704-709.

120. Giraldi A, Rellini A, Pfaus JG, et al. Questionnaires for assessment of female sexual dysfunction: a review and proposal for a standardized screener. J Sex Med 2011; 8: 2681-2706. 